\title{
Thermal integration of PEM Fuel Cells and metal hydrides storage system for Zero Emission Ultimate Ship (ZEUS)
}

\author{
Matteo Cavo ${ }^{1}$,Eleonora Gadducci ${ }^{1}$, Massimo Rivarolo $^{1}$, Loredana Magistri $^{1}$, Andrea Dellacasa $^{2}$, Matteo Romanello $^{2}$, \\ Gerardo Borgogna², and Christian Davico ${ }^{2}$
}

${ }^{1}$ Thermochemical Power Group (TPG), DIME, University of Genoa, Via Montallegro 1, 16145 Genoa, Italy

${ }^{2}$ Fincantieri S.p.A., via Cipro 11, 16129 Genoa, Italy

\begin{abstract}
The ZEUS (Zero Emission Ultimate Ship), developed in the framework of the national research project TecBia conducted by Fincantieri and co-founded by Italian Ministry of Economic Development, is a $25 \mathrm{~m}$ length vessel characterized by a zero-emissions propulsion system. The on-board power generation is provided by 4 PEM Fuel Cell modules ( $140 \mathrm{~kW}$ power installation) fed by hydrogen stored into 48 Metal Hydride tanks (MH). PEMFC and MH thermal systems are coupled to recover the heat produced by PEMFC and to feed the endothermic dissociation reactions of hydrogen from MHs. This paper provides a Matlab-Simulink model to simulate the dynamic behaviour of the PEMFC power generation system and the thermal coupling with MH racks installed onboard. Three typical operative profiles are simulated to verify the thermal management control system and the impact of transient conditions on the propulsion plant. Furthermore, the effects of the major exogenous parameters are investigated. Results verify that thermal coupling between the two systems is guaranteed; however, an excessive load increase can lead the stacks to operate under non-optimal conditions for significant periods of time. The effect of exogenous parameters has been verified to be negligible and does not significantly affect the control system.
\end{abstract}

\section{Introduction}

In the last years, global $\mathrm{CO}_{2}$ emissions have been growing significantly due to anthropogenic activities, reaching the record values of 33.5 and 33.4 Gtons in 2018 and 2019 respectively [1]. The impact of maritime transportation has increased in the last years, due to the fact that $99 \%$ of the ships in operation still employ traditional high-pollutant fuels for propulsion, as reported in [2]. In the Fourth Greenhouse Gas Study (2020), the International Maritime Organization (IMO) has recently reported that Greenhouse Gas (GHG) emissions of total shipping have increased from 977 million tonnes in 2012 to almost 1.1 Gtons in 2018 (9.6\% increase) [3]. The same IMO, as main regulator authority at international level in maritime sector, has recently defined long-term targets to reduce by $50 \%$ GHG emissions from shipping by 2050 , compared to 2008 levels [4].

To reach this ambitious target, the introduction of alternative fuels and the diffusion of new technologies has a primary importance role. The introduction of LNG to replace fuel oil in internal combustion engines (ICE) will help to reduce $\mathrm{CO}_{2}$ emissions, but it is not sufficient to reach the target: thus, different more sustainable solutions are under analysis. Recent studies in literature highlighted the possibility of employing fuel cell systems, fed by methanol $[5,6]$, biogas $[7,8]$ or hydrogen $[9,10]$, while other authors developed algorithms to compare different fuels by adopting multi-criteria approaches
[11,12], considering technical, environmental and economic aspects $[13,14]$. Among the different choices, Proton Exchange Membrane Fuel Cells (PEMFC), fed by pure hydrogen, present several advantages, such as low noise and vibrations, zero pollutant and $\mathrm{CO}_{2}$ emissions, fast response to load variations and high compactness. Considering their strong potential, their possible application in ships, in particular for sizes up to $1 \mathrm{MW}$, has been investigated by many authors $[15,16,17,18,19]$.

A critical point in the use of PEMFC in maritime application is the high volumes related to hydrogen storage: this aspect can be a limitation both in case of compressed high-pressure tanks and liquid storage at cryogenic vessels for liquid storage $(20 \mathrm{~K})$. Metal Hydrides (MH) represent an interesting alternative storage method, as they allow for a good energy storage in terms of volume, without needing high amounts of energy since $\mathrm{H}_{2}$ is stored at limited pressure $(<40$ bar) and ambient temperature [20,21,22]. The main drawback is the considerable weight of $\mathrm{MH}$ tanks; however, this aspect can be limited by properly positioning the tanks onboard the ship [23,24].

As $\mathrm{H}_{2}$ release by $\mathrm{MH}$ needs thermal energy and the PEMFC is characterized by heat production during operations, their thermal coupling has been investigated by many authors [25,26,27], mostly in stationary applications; more recently, the authors developed a model for the integration for maritime application, referred to the ZEUS research vessel [28], developed in

\footnotetext{
Corresponding author: matteo.cavo@edu.unige.it
} 
the framework of the national research project TecBia (Technologies at low environmental impact for energy production on ships), financed by Fincantieri-Isotta Fraschini Motori S.p.A. and Italian Ministry of Economic Development (MISE), as part of "National Operational Programme (PON) 2014/2020 Large R\&D Projects". The ZEUS is fully powered by PEMFCs (installed power 140 $\mathrm{kW})$ and $\mathrm{H}_{2}$ is stored onboard by $\mathrm{MH}$.

Fig. 1 shows the simplified system layout. The two PEMFC modules are connected to the main hydraulic system through the WGHE heat exchangers, where a mix $50 \%$ water- $50 \%$ glycol circulates. The main hydraulic system is responsible for the heat transfer from the PEMFC to the MH tanks, in a closed-loop system. Depending on the thermal energy available, the MH tanks release a determined amount of hydrogen, which is needed to supply the PEM stacks. The heat exchanger WHSE, fed by seawater at the cold side, assures the thermal equilibrium in the whole system, dissipating the eventual exceeding heat.

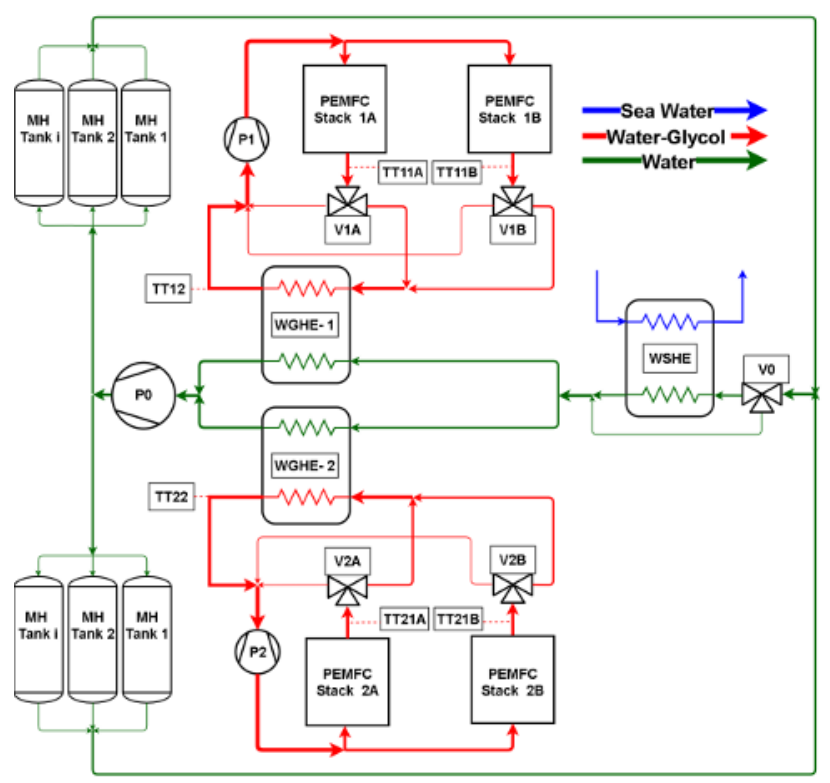

Fig. 1. ZEUS energy system description.

This paper aims to investigate the interaction between the PEMFC system and the MH considering different load profiles, to verify possible critical conditions.

\section{Model based approach}

In this section the main operating and modelling approaches of the PEM fuel cell and metal hydride thermal coupling system are discussed. Additionally, a description of the control logic to guarantee the proper operation of the PEMFC modules is presented: in this application, a proportional-integral (PI) control logic is proposed. The aim of this study is to verify the ability of the heat dissipated by the PEMFCs to activate and sustain the endothermic hydrogen release reactions involving the metal hydride cylinders. Critical conditions may occur in case of excessive power ramps: temperature peaks lead to irreversible deterioration of the polymeric membrane of the fuel cell stacks. In addition, the effect of an exogenous parameter affecting the system's ability to release heat is investigated: the seawater temperature.

\subsection{Model description and control strategy}

The assumptions used to develop the model are set out below.

- All models are 0D representations of real components; therefore, temperature gradients and velocity profiles are not considered.

- Heat losses to the environment are neglected.

- The representation of the thermal control circuit of the PEMFC modules and the MH heating circuit does not consider the fluid-dynamic delays. This is justified by the fact that the delays due to fluid accumulation are several orders of magnitude lower than the thermal dynamics affecting the working fluid.

The physical and mathematical approaches are described in [28]. The fuel cell and metal hydride tank models were validated according to experimental data provided by the respective suppliers, as shown in [28]. The control strategy designed for the system must guarantee the temperature set points required by the cells to ensure the correct humidity condition of the polymer membrane. The control is performed through two basic logics:

- Temperature control at PEMFC stacks outlet: to avoid irreversibly damaging the polymeric membranes due to temperature peaks at high load, the temperature of the water-glycol at stacks outlet must be controlled. As shown in Fig. 1, this is possible through the partialisation of valves V1A and V1B of branch 1 and $\mathrm{V} 2 \mathrm{~A}$ and $\mathrm{V} 2 \mathrm{~B}$ of branch 2. Integral proportional controllers measure the error between the temperature signal of TT11A and TT11B at branch 1, TT21A and TT21B at branch 2: then it regulates the mass fraction which bypasses the WGHE.

- Temperature control at the outlet of the WGHE: to avoid critical operating conditions of stacks temperature control valves, the temperature of the water-glycol at WGHE outlet must be controlled. The V0 actuator modifies the fluid flow rate that passes through the water-sea exchanger according to the difference between the mean temperature measured by the TT12 and TT22 sensors and the set point temperature.

The mathematical approach of PI controllers can be described by transfer functions in relation to the error [29]. The characteristic parameters of the controller are derived following the "Ziegler-Nichols Oscillatory" calibration method.

\subsection{Case studies}

In this section, the case studies are described; all the data required to carry out the simulations are provided in [28]. The forcing of the system is the current set on the stacks. Since every current point corresponds to an electrical power (as in Table 1), for each forced current ramp there is an electrical power ramp. The first case study (CASE A) refers to a current ramp which leads the stacks to deliver the minimum power, starting from the nominal 
power. The second case study (CASE B) refers to a current ramp that leads the stacks to deliver the nominal power, starting from the minimum power. Finally, in CASE $\mathrm{C}$ the effect on the main control variables of the system caused by variations in seawater temperature is investigated. All simulations are based on the assumption of equilibrium conditions and a $100 \%$ initial metal hydride state of charge. Ramps proceed at a 50A/s velocity: this is the limit suggested by the PEMFC supplier.

Table 1. Summary of working points and case studies.

\begin{tabular}{|c|c|}
\hline Current & Power \\
\hline $400 \mathrm{~A}$ & Nominal Power $(\sim 60 \mathrm{~kW})$ \\
\hline $120 \mathrm{~A}$ & Minimum Power $(\sim 17 \mathrm{~kW})$ \\
\hline \multicolumn{2}{|r|}{ Case studies } \\
\hline CASE A & Nominal Power $\rightarrow$ Minimum Power \\
\hline CASE B & Minimum Power $\rightarrow$ Nominal Power \\
\hline CASE C & Effects of seawater temperature \\
\hline
\end{tabular}

\section{Results}

The simulations carried out aim to investigate the most critical operating conditions of the thermal management system of the PEMFC plant coupled to the metal hydride racks. Results are hereby presented, some important considerations must be pointed: (i) CASE A can be considered a safe and suitable ramp for the thermal management system; (ii) CASE B outcomes critical operating conditions of fuel cell stacks during transients; (iii) CASE $\mathrm{C}$ simulations prove the robustness of the thermal management system, which reacts appropriately to different sea water temperatures.

\subsection{CASE A}

The system is considered to be in equilibrium at nominal power and MHs fully charged. The aim is to verify that the control system can handle the load variation and move the plant to a balanced state avoiding critical operating conditions.
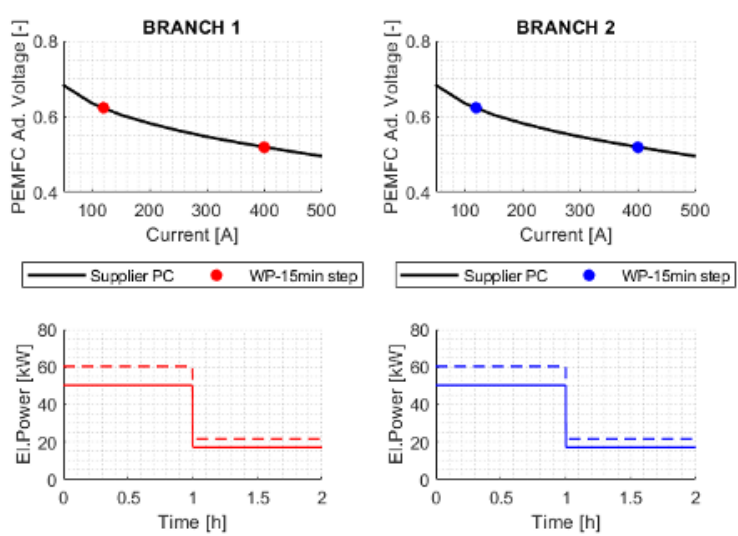

- NET - - - GROSS

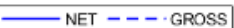

Fig. 2. Forcing and electrical power as a function of simulation time (CASE A). PEMFC Ad.Voltage has been obtained dividing cell voltage by Nernst electric potential.


Fig. 3. PEMFC outlet temperature and V2 bypass mass fraction as function of simulation time (CASE A).

Figures 2 and 3 show the electrical power and stacks outlet temperature during CASE A current ramp. The working point (WP) is plotted every $15 \mathrm{~min}$ above the polarization curve (PC) provided by the stack supplier. As the current gets lower, the electrical power decreases as well (Figure 2); also, the heat dissipated by the fuel cells drops, so the control system must react to guarantee the set point temperature (Figure 2). V2A and V2B valves regulate the amount of water-glycol which bypasses the heat exchanger; so, for lower loads more fluid has to skip the WGHE (Figure 3). The control system restores the equilibrium in about 3 minutes. The maximum temperature variation with respect to the set point desired by the cells is about $1.5^{\circ} \mathrm{C}$ : this working condition does not cause stress to the PEMFC modules. 

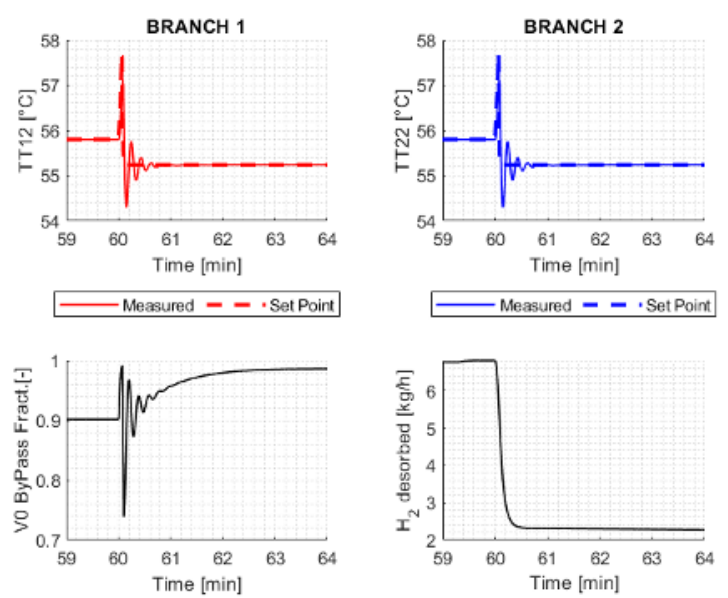

Fig. 4. WGHE glycol outlet temperature, V0 bypass mass fraction and hydrogen desorption flow as function of simulation time (CASE A).

Figure 4 shows the behaviour of the water-glycol temperature at WGHE outlet. Restricting this temperature is essential to prevent excessive stress on the control system of the V2A and V2B valves. During load drops, the flow rate through the WGHE is lower; therefore, in order to guarantee the set point temperature, it is necessary to decrease the inlet water temperature of the heat exchanger's cold side. So, valve V0 bypasses less water to the seawater exchanger. Metal hydrides release less hydrogen due to a reduction of thermal power dissipated from the fuel cells; anyway, it is sufficient to feed the electrochemical reactions happening in the working stacks at the PEMFC standard operating pressure. The simulation outcomes that the temperature measured by TT3A is handled promptly and efficiently by the control system.

\subsection{CASE B}

The system is considered to be in equilibrium at minimum power and MHs fully charged. Under this operating condition, it is important to verify that the rise in electrical load does not lead to a substantial raise in stack cooling circuit temperatures for extended periods of time; otherwise, the membrane would dry out and this shortens the lifetime of the cell.
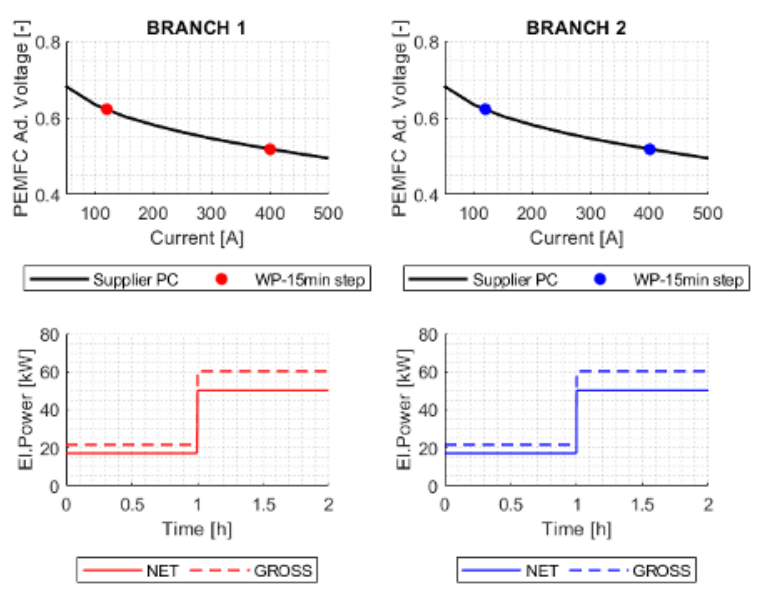

Fig. 5. Forcing and electrical power as a function of simulation time (CASE B). PEMFC Ad.Voltage has been obtained dividing cell voltage by Nernst electric potential.
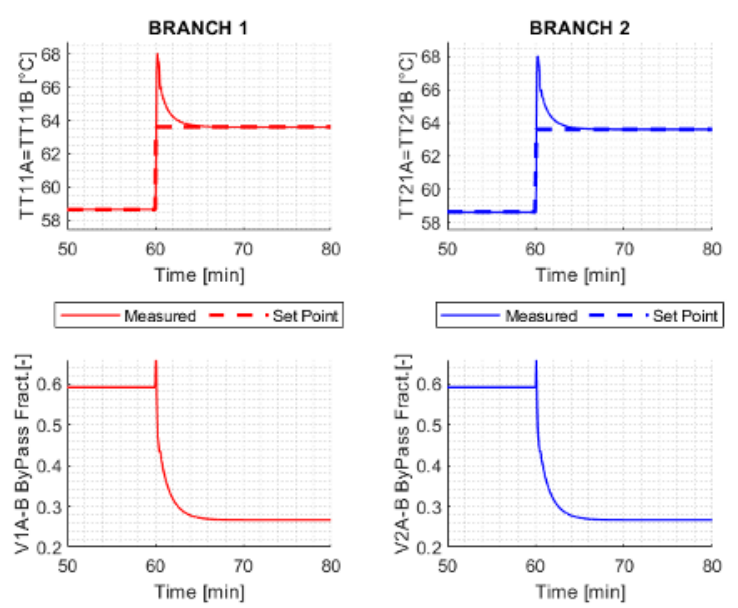

Fig. 6. PEMFC outlet temperature and V2 bypass mass fraction as a function of simulation time (CASE B).

Figures 5 and 6 outline the effects of load increase during transient conditions. The working point (WP) is plotted every $15 \mathrm{~min}$ above the polarization curve (PC) provided by the stack supplier. Since the electrical power output rises, the heat produced by the stack increase. V2A and V2B valves tends to let pass more fluid to the WGHE (Figure 6) to reach the set point desired, but mechanical delays and the dynamic of the system lead to a peak of water-glycol temperature at stack inlet: $4^{\circ} \mathrm{C}$ higher than the desired one. The overall time to reach the new equilibrium point is about 3 minutes. So, it results that the cells work under critical conditions for a long time at CASE B. Two possible solutions can be adopted to avoid this phenomenon: reducing the speed of power increment or introducing intermediate load steps. Here, the battery shall offset the lack of energy for the duration required to attain the nominal operating condition. 

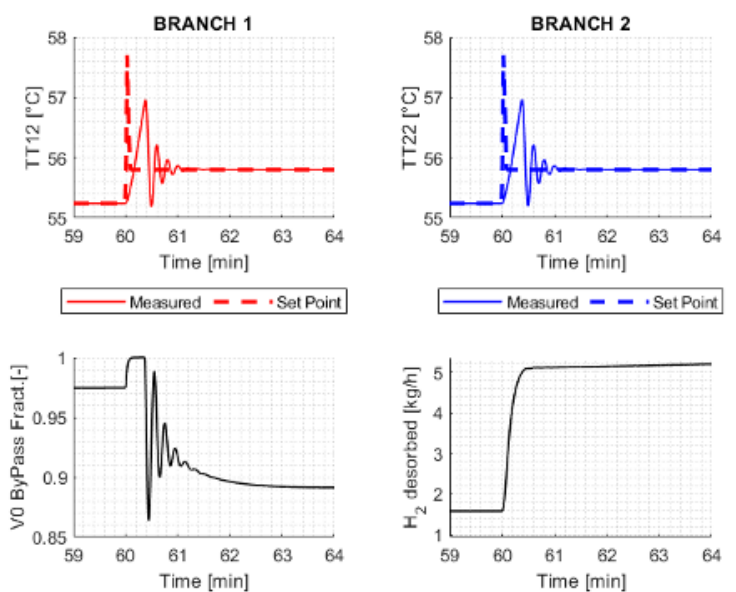

Fig. 7. WGHE glycol outlet temperature, WSHE water flow and hydrogen desorption flow as a function of simulation time (CASE B).

WGHE outlet temperature is controlled properly, and the maximum deviation is neglectable. Control valve V0 manages to guarantee the set point by increasing the water flow to the WSHE (Figure 7). Differently from CASE A, as the load rises, the heat flux dissipated by the fuel cells increases, resulting in more hydrogen being extracted from the metal powder.

\subsection{CASE C}

PI are robust control systems which base their response on the error between a measured variable and the desired set point. Therefore, any exogenous component might overcome the control systems. Sea water temperature is one of the most influencing factors: in the Mediterranean Sea it ranges from an average value of approximately $15^{\circ} \mathrm{C}$ during winter to $25^{\circ} \mathrm{C}$ for summer. In this section different load ramps are computed from minimum to nominal power at three different sea water temperatures: $15^{\circ} \mathrm{C}, 20^{\circ} \mathrm{C}$ and $25^{\circ} \mathrm{C}$. The role of $\mathrm{V0}$ valve is to adjust the mass fraction bypassing the WSHE to avoid temperature fluctuations and critical operations in the stack water-glycol cooling circuit. As shown in Figure 8, the behaviour of valves V1A, V1B and V2A, V2B is not affected by the variation of the seawater temperature: the V0 control system acts promptly and efficiently (Figure 9). Furthermore, the water flow rate through the seawater exchanger decreases as the sea temperature increases, while the hydrogen released by the MHs is not affected.
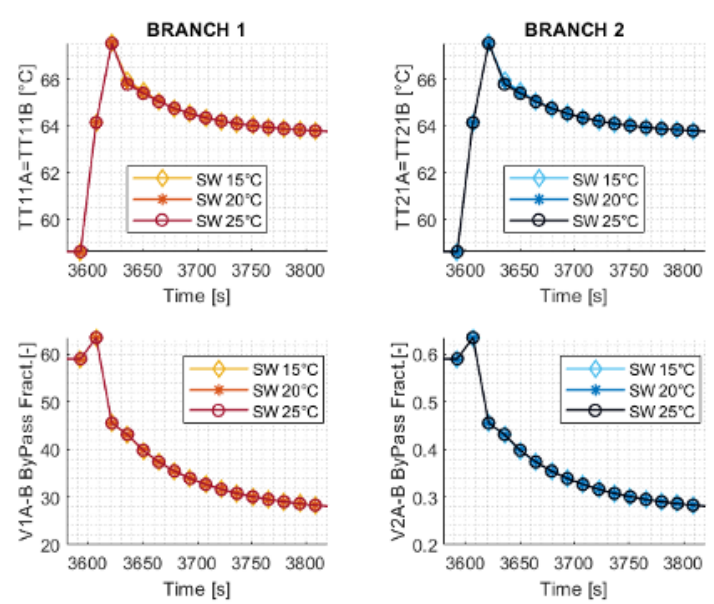

Fig. 8. Comparison of V1A, V1B, V2A and V2B control valves at different sea water temperatures.


Fig. 9. Comparison of V0 control valve and hydrogen desorption at different sea water temperatures.

\section{Conclusions}

Exploring critical areas of operation of the ZEUS propulsion system and determining their causes is the first step towards a robust and effective control system. In this paper, a Matlab Simulink dynamic model is employed to analyse the behaviour of the thermal coupling system between PEM-type fuel cells and metal hydride tanks. The main elements constituting the circuit have been realised and validated based on data provided by the suppliers. The simulations computed explore the most severe operating conditions the yacht may experience, moving from nominal to minimum load and vice versa. Also, the effect of an important exogenous parameter that can affect system operation is analysed: the seawater temperature is varied from $15^{\circ} \mathrm{C}$ to $25^{\circ} \mathrm{C}$ in the worst operating condition (load increment).

Results show that, when the boat switches from nominal to minimum power, the control system manages this new equilibrium point avoiding critical transients. When the system switches from minimum to nominal power, a long-lasting temperature peak occurs in the cooling circuit of the PEMFC stacks. Temperature set 
points are determined by the manufacturer to ensure an ideal membrane humidity level; therefore, this phenomenon could cause permanent degradation of the polymer membrane contained in the fuel cells. A few possible solutions have been identified and will be tested in future works: introducing intermediate steps, load ramps with reduced advance rates or analysing the performance of a model predictive controller (MPC) and comparing this control technique to the previous one. Finally, it has been highlighted the effect of sea water on the control system does not have a significant impact. This proves the robustness of the PI control under environmental conditions beyond the design point.

This work becomes particularly relevant as it explores the operational limits of the hybrid PEMFCs energy system installed on board the ZEUS. In addition, it will be possible to test the reliability of the model computations basing on the ship real data, providing a powerful tool to perform predictions leading to improvements in the control system, preventing from damage, extending both PEMFC and $\mathrm{MH}$ lifetimes.

This work has been partially supported by Fincantieri S.p.A. and Italian Ministry of Economic Development through the research project TecBia, CUP n.B98I17000680008.

\section{References}

1. www.iea.org last access $8 / 9 / 2021$.

2. Maritime forecast to 2050, DNV, available at https://eto.dnv.com/2021.

3. https://www.imo.org/en/OurWork/Environment/Page s/Fourth-IMO-Greenhouse-Gas-Study-2020.aspx last access 8/9/2021.

4. https://www.imo.org/en/MediaCentre/HotTopics/Pag es/Reducing-greenhouse-gas-emissions-fromships.aspx last access 8/9/2021.

5. N.R. Ammar, Transportation Research, Transport Environ., 69 (2019), 66-76.

6. M. Santin, A. Traverso, L. Magistri, App. Energy, 86 (2009), 2204-2212.

7. L. Mantelli, M.L. Ferrari, A. Traverso, App. Thermal Engineering, 191 (2021), 1-14.

8. A.F. Massardo, L. Magistri, Int. J. of Engineering for gas Turbine and Power, 125 (2003), 67-74.

9. L.E. Klebanoff, J.W. Pratt, C.M. Leffers, K.T. Sonerholm, T. Escher, J. Burgard, S. Ghosh, Transportation Research, Transport Environ., 54 (2017), 250-268.

10. M. Rivarolo, D. Rattazzi, T. Lamberti, L. Magistri, Int. J. of Hydrogen En., 45 (2020), 25747-25757.

11. M. Baumann, M.Weil, J.F. Peters, N. ChibelesMartins, Antonio B. Moniz, Renewable and Sust. En. Reviews, 107 (2019), 516-534.

12. R. Chauvy, R. Lepore, P. Fortemps, G. De Weireld, Sust. Prod. and Consumption, 24 (2020), 194-210.

13. A. Priftis, E. Boulougouris, O. Turan, A. Papanikolau, Ocean Engineering, 156 (2018), 347-357.
14. M. Rivarolo, D. Rattazzi, L. Magistri, A.F. Massardo, En. Conv. And Management, 244 (2021), 114506.

15. O.B. Inal, C. Deniz, J. of Cleaner Prod., 265 (2020), 121734.

16. Nazir H, Muthuswamy N, Louis C, Jose S, Prakash $\mathrm{J}$, Buan MEM, et al., Int J Hydrogen Energy, 45 (2020), 28217-28239.

17. Pfeifer A, Prebeg P, Duić N., ETransportation, 3 (2020), 100048.

18. Nuchturee C, Li T, Xia H., Renew Sustain Energy Rev, 134(2020), 110145.

19. Wu P, Bucknall R., Int J Hydrogen Energy, 45(2020), 3193-3208

20. Chabane D., et al., Int. J. of Hydrogen Energy, 44 (2019), 1034-1046.

21. K. Manickam et al., Int. J. of Hydrogen Energy, 44 (2019), 7738-7745.

22. S.N. Nyamsi, M. Lototskyy, I. Tolj, Int. J. of Hydrogen Energy, 43 (2018), 22568-22583.

23. J.B. von Colbe, et al., Int. J. of Hydrogen Energy, 44 (2019), 7780-7808.

24. C. Fiori, A. Dell'Era, F. Zuccari, A. Santiangeli, A. D'Orazio, F. Orecchini, Int. J. of Hydrogen Energy, 40 (2015), 11879-11889.

25. P. Rizzi, E. Pinatel, C. Luetto, P. Florian. A. Graizzaro, S. Gagliano, M. Baricco, , J. of Alloy and Compounds, 645 (2015), 338-342.

26. F. Mahmoodi, R: Rahimi, App. Thermal Engineering, 178 (2020), 115490.

27. T. Førde, J. Eriksen, A.G. Pettersen, P.J.S. Vie, Ø. Ulleberg, Int. J. of Hydrogen En., 34 (2009), 67306739.

28. M. Cavo, E. Gadducci, D. Rattazzi, M. Rivarolo, and L. Magistri, Int. J. Of Hydrogen Energy, 46 (2021), 32630-32644.

29. G. Goodwin, S. Graebe, M. Salgado, Control System Design (Valparaiso: Prentice Hall, 2000). 